\title{
Partitioned Methods in Computational Modelling on Fluid-Structure Interactions of Concrete Gravity-Dam
}

\author{
W. Z. $\operatorname{Lim}^{1}$, R. Y. Xiao ${ }^{1}$, T. Hong ${ }^{1} \&$ C. S. Chin ${ }^{2}$ \\ ${ }^{1}$ Department of Urban Engineering, London South Bank University, London, UK \\ ${ }^{2}$ Department of Civil Engineering, Xi'an Jiaotong-Liverpool University, Jiangsu Province, China \\ Correspondence: R. Y. Xiao, Department of Urban Engineering, London South Bank University, SE1 0AA, \\ London, UK. E-mail: xiaor2@1sbu.ac.uk
}

Received: June 2, 2013 Accepted: October 23, 2013 Online Published: October 30, 2013

doi:10.5539/cis.v6n4p154

URL: http://dx.doi.org/10.5539/cis.v6n4p154

\begin{abstract}
Fluid-structure interaction (FSI) has resulted in both complex applications and computing algorithmic improvements. The aim of this paper is to develop a better understanding of the fluid-structure interaction behaviour and the numerical coupling methods which can be used in analysing the FSI problem of a multi-physics nature computationally. There are two different systems in partitioned methods for coupling the fluid and structural domains which use strong and weak couple algorithms. Numerical results have been obtained on the hypothetical models for the close and open-spillways concrete gravity-dam. The two-way coupling partition method has been applied to the dynamic velocity flow and pressure using the ANSYS FEA software. A close comparison between the weak and strong coupled systems of two-way partitioned method has been made for the consideration of both close and open-spillways concrete gravity-dam.
\end{abstract}

Keywords: partitioned method, fluid-structure interaction, concrete gravity-dam, computational modelling

\section{Introduction}

Fluid-structure interaction, FSI, can be described as the coupling of fluid mechanics and structure mechanics. FSI problems possess the classical multi-physics characteristics which occur in many engineering applications such as aerodynamics, wave-propagation, wind turbines, bio-engineering, offshore structures and bridges. In general, FSI or multi-physics problems can be solved with either experimental or numerical simulations. The advance on Computational Fluid Dynamics (CFD) and Computational Structure Dynamics (CSD) has allowed the numerical simulations of FSI to be conducted rapidly. The technique for the simulation of FSI has two distinctive approaches: the monolithic and partitioned approaches (Thomas, 2010). However, only the partitioned approach will be adopted in this paper for the FSI numerical examples. The partitioned approach in general can be categorised into weakly or strongly coupled problems. The coupling can be divided into one-way or two-way coupling cases. Although there are many existing methods and techniques in FSI applications (Friedrich-Karl et al., 2010; Joris et al., 2010; Bathe et al., 2009; Michler et al., 2003; Wulf \& Djordje, 2008; Jo et al., 2005; Sandboge, 2010; Mitra, 2008; Akkose et al., 2008; Broderick \& Leonard, 1989; Onate et al., 2007), the focus of this paper is to investigate the differences of the partitioned two-way coupling method for the weakly and strongly coupled system. The finite element method, FEM has been adopted with consideration of the Lagrangian and Arbitrary Lagrangian-Euler (ALE) methods. ALE formulations have been used as the numerical technique in investigating and analysing the FSI problem. The partitioned method of the FSI problems has been used in ANSYS software where both fluid and structural domains are set up separately and interacted with the coupled field methods of Multi-Field Single-Code Solver (MFS) and load transfer physics environment.

\section{Fluid Structure Interaction Approach}

The basic principle of couple-field analysis or multi-physics analysis is the combination of analysis from different engineering disciplines or physics that interact with each other to solve a widely known engineering problem such as FSI. The partitioned method is an approach in which the two distinctive solvers (fluid and structure) are activated separately for the fluid flow and the displacement of a structure. The fluid and structure equations are solved by integratation in time. Interface conditions are enforced asynchronously which means that the fluid's flow does not change while the solution of the structural equations is calculated and vice versa. This 
approach preserves the software modularity and requires a coupling algorithm to allow for the interaction and to determine the solution of the coupled problem where solution results can be transferred between the two solvers (Thomas, 2010).

In general, the partitioned method can be categorised into two different types of coupling algorithms: staggered or weakly coupled and iterative staggered or strongly coupled. Weak coupling divides into one-way and two-way coupling systems. The focus of this research will be entirely focused on the two-way coupling system when both fluid and structure are allowed to be fully interacted. In the two-way coupling calculations, fluid pressure acting on the structure is transferred to the structure solver and the displacement of the structure is also transferred into the fluid solver.

\subsection{Weak Coupling}

The weak or staggered coupling can be shown in Figure 1. In each time-step from $t_{n}$ to $t_{n+1}$, both $\Omega_{f}$ and $\Omega_{s}$ are solved separately. Under this assumption, the flow solution, $\Omega_{\mathrm{f}}$ at time $t_{\mathrm{n}}$ is fully dependent on the flow and same as structure solution $\Omega_{\mathrm{s}}$ at time $t_{n}$. However, the interaction at time $t_{n+1}$ is not taken into account and the same approach applies for the structure problem. One advantage of the partitioned approach is that different solvers can be used for different multi-physics fields. The convergence at the boundary between structure and fluid is not considered and a new time step is directly launched. The weakly coupled approach solves every sub-problem (fluid and structure) per time-step and such approach is a generic explicit approach.

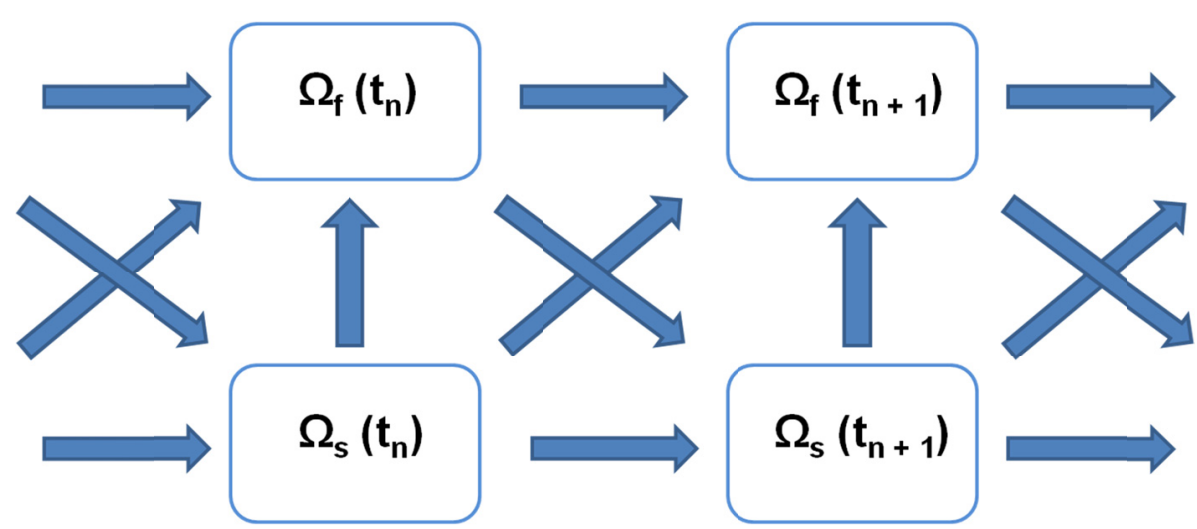

Figure 1. Weak partitioned solution of the coupled system

\subsection{Strong Coupling}

The interface between both domains is crucial in most applications of a strong coupling system. This system can allow parallel solution of a fluid and a structure domain. A strong coupled system is a further development of the partitioned approach of which two domains are solved independently in a decoupled approach with an iterative manner i.e. an interaction loop between each time-step (Thomas, 2010). The coupled system is shown in Figure 2. The basic iterative algorithm can be referred to in Thomas (2010).

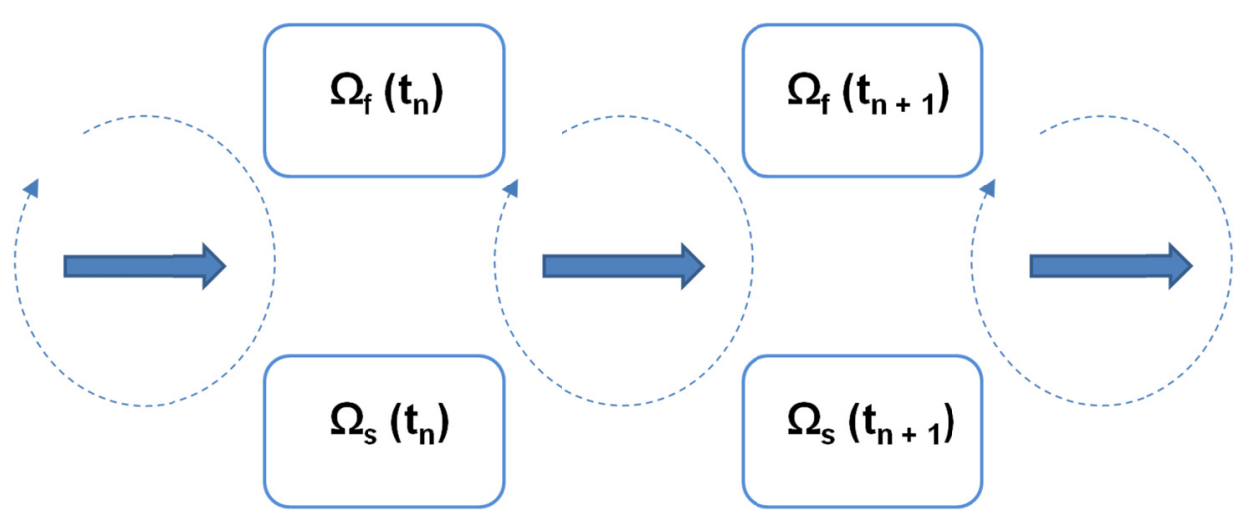

Figure 2. Strong partitioned solution of the coupled system 


\section{Computational Techniques}

The analytical solutions of structural and fluid domains have both been conducted by ANSYS FLOTRAN-CFD and STRUCTURAL solution, respectively. Relevant element types used are element SOLID185 for the concrete dams and element FLUID142 for the reservoir fluid flow. Both SOLID185 and FLUID142 elements are compatible in relation to the coupling method of fluid interaction with solid structure in three dimensional models. The SOLID185 element is generally used for 3-D modelling of solid structures and it is defined by eight nodes having three degrees of freedom at each node: translations in the nodal $\mathrm{x}, \mathrm{y}$, and $\mathrm{z}$ directions. The element has plasticity, hyperelasticity, stress stiffening, creep, large deflection, and large strain capabilities. It also has got mixed formulation capability for simulating deformations of nearly incompressible elasto-plastic materials, and fully incompressible hyperelastic materials (ANSYS Inc., 2009).

As for the FLUID142 element, it is defined by eight nodes and the material properties of the fluid density and viscosity. FLUID142 can model transient or steady state fluid/thermal systems that involve fluid and/or non-fluid region as well as the problem of fluid-solid interaction analysis with degrees of freedom: velocity and pressure. By using the FLUID142 element, the velocities are obtained from the conservation of momentum principle, and the pressure is obtained from the conservation of mass principles (ANSYS Inc., 2009) which are described in the governing equations below.

\subsection{Fluid Flow Governing Equations}

The fluid flow is defined by the laws of conservation of mass, momentum, and energy. Such laws are expressed in terms of partial differential equations which are discretised with a finite element based technique. The fluid flow equations are governed by Navier-Stokes equations of incompressible flow.

The continuity equation of the fluid flow is shown in (ANSYS Inc., 2009) as the following:

$$
\frac{\partial \rho}{\partial t}+\frac{\partial\left(\rho_{\mathrm{v}_{X}}\right)}{\partial x}+\frac{\partial\left(\rho_{\mathrm{v}_{\mathrm{y}}}\right)}{\partial \mathrm{y}}+\frac{\partial\left(\rho_{\mathrm{v}_{\mathrm{Z}}}\right)}{\partial \mathrm{z}}=0
$$

where $V_{x}, V_{y}$ and $V_{z}$ are the components of the velocity vector in the $x, y$ and $z$ direction, respectively. $\rho$ is the density of the fluid and $t$ is the time shown in the equation above. The rate of change of density can be replaced by the rate of change of pressure:

$$
\frac{\partial \rho}{\partial \mathrm{t}}=\frac{\partial \rho}{\partial \mathrm{P}} \frac{\partial \mathrm{P}}{\partial \mathrm{t}}
$$

As for the incompressible solution:

$$
\frac{\mathrm{d} \rho}{\mathrm{dP}}=\frac{1}{\beta}
$$

where $P$ and $\beta$ are the pressure and bulk modulus of the fluid flow, respectively.

In a Newtonian fluid, the relationship between the stress and rate of deformation of the fluid is shown in (ANSYS Inc., 2009) as:

$$
\tau_{i j}=-P_{i j}+\mu\left(\frac{\partial_{u i}}{\partial_{x j}}+\frac{\partial_{u j}}{\partial_{x i}}\right)+\delta_{i j} \lambda \frac{\partial_{u i}}{\partial_{x i}}
$$

where $\tau_{i j}, P, U_{i}, \mu$ and $\lambda$ represent the stress tensor, the fluid pressure, orthogonal velocities $\left(u_{1}=V_{x}, u_{2}=\right.$ $V_{y}=, u_{3}=V_{z}$ ), dynamic viscosity and second coefficient of viscosity, respectively. The product of the second coefficient of viscosity and the divergence of the velocity is zero for a constant density fluid. Equation (4) transforms the momentum equations to the Navier-Stokes equations as follows (ANSYS Inc., 2009):

$$
\begin{aligned}
& \frac{\partial \rho_{V_{x}}}{\partial t}+\frac{\partial\left(\rho_{V_{x} V_{x}}\right)}{\partial x}+\frac{\partial\left(\rho_{V_{y} V_{x}}\right)}{\partial y}+\frac{\partial\left(\rho_{V_{z} V_{x}}\right)}{\partial z}=\rho_{g_{x}}-\frac{\partial P}{\partial x} \\
& { }_{R_{x}}+\frac{\partial}{\partial x}\left(\mu_{e} \frac{\partial V_{x}}{\partial x}\right)+\frac{\partial}{\partial y}\left(\mu_{e} \frac{\partial V_{x}}{\partial y}\right)+\frac{\partial}{\partial z}\left(\mu_{e} \frac{\partial V_{x}}{\partial z}\right)+T_{x}
\end{aligned}
$$




$$
\begin{aligned}
& \frac{\partial \rho \mathrm{V}_{\mathrm{y}}}{\partial \mathrm{t}}+\frac{\partial\left(\rho \mathrm{V}_{\mathrm{x}} \mathrm{V}_{\mathrm{y}}\right)}{\partial \mathrm{x}}+\frac{\partial\left(\rho \mathrm{V}_{\mathrm{y}} \mathrm{V}_{\mathrm{y}}\right)}{\partial \mathrm{y}}+\frac{\partial\left(\rho \mathrm{V}_{\mathrm{z}} \mathrm{V}_{\mathrm{y}}\right)}{\partial \mathrm{z}}=\rho \mathrm{g}_{\mathrm{y}}-\frac{\partial \mathrm{P}}{\partial \mathrm{y}} \\
& +\mathrm{R}_{\mathrm{y}}+\frac{\partial}{\partial \mathrm{x}}\left(\mu_{\mathrm{e}} \frac{\partial \mathrm{V}_{\mathrm{y}}}{\partial \mathrm{x}}\right)+\frac{\partial}{\partial \mathrm{y}}\left(\mu_{\mathrm{e}} \frac{\partial \mathrm{V}_{\mathrm{y}}}{\partial \mathrm{y}}\right)+\frac{\partial}{\partial \mathrm{z}}\left(\mu_{\mathrm{e}} \frac{\partial \mathrm{V}_{\mathrm{y}}}{\partial \mathrm{z}}\right)+\mathrm{T}_{\mathrm{y}} \\
& \frac{\partial \rho \mathrm{V}_{\mathrm{Z}}}{\partial \mathrm{t}}+\frac{\partial\left(\rho \mathrm{V}_{\mathrm{X}} \mathrm{V}_{\mathrm{Z}}\right)}{\partial \mathrm{x}}+\frac{\partial\left(\rho \mathrm{V}_{\mathrm{y}} \mathrm{V}_{\mathrm{Z}}\right)}{\partial \mathrm{y}}+\frac{\partial\left(\rho \mathrm{V}_{\mathrm{Z}} \mathrm{V}_{\mathrm{Z}}\right)}{\partial \mathrm{z}}=\rho \mathrm{g}_{\mathrm{Z}}-\frac{\partial \mathrm{P}}{\partial \mathrm{z}} \\
& +\mathrm{R}_{\mathrm{Z}}+\frac{\partial}{\partial \mathrm{x}}\left(\mu_{\mathrm{e}} \frac{\partial \mathrm{V}_{\mathrm{z}}}{\partial \mathrm{x}}\right)+\frac{\partial}{\partial \mathrm{y}}\left(\mu_{\mathrm{e}} \frac{\partial \mathrm{V}_{\mathrm{z}}}{\partial \mathrm{y}}\right)+\frac{\partial}{\partial \mathrm{z}}\left(\mu_{\mathrm{e}} \frac{\partial \mathrm{V}_{\mathrm{z}}}{\partial \mathrm{z}}\right)+\mathrm{T}_{\mathrm{z}}
\end{aligned}
$$

where $g, R$ and $T$ represent the acceleration due to gravity, distributed resistances and viscous loss terms, respectively with subscript $x, y$ and $z$ as the coordinates. The density of the fluid properties and effective viscosity are presented as $\rho$ and $\mu_{e}$, respectively. The viscous loss term, $T$ for all coordinate directions is eliminated in the incompressible, constant property case. The order of the differentiation is reversed in each term, reducing the term to a derivative of the continuity equation, where it is zero.

The energy equation for the incompressible is shown in (ANSYS Inc., 2009) as:

$$
\begin{aligned}
& \frac{\partial}{\partial t}\left(\rho \mathrm{C}_{\mathrm{p}} \mathrm{T}\right)+\frac{\partial}{\partial \mathrm{x}}\left(\rho \mathrm{V}_{\mathrm{x}} \mathrm{C}_{\mathrm{p}} \mathrm{T}\right)+\frac{\partial}{\partial \mathrm{y}}\left(\rho \mathrm{V}_{\mathrm{y}} \mathrm{C}_{\mathrm{p}} \mathrm{T}\right)+\frac{\partial}{\partial z}\left(\rho \mathrm{V}_{\mathrm{Z}} \mathrm{C}_{\mathrm{p}} \mathrm{T}\right) \\
& =\frac{\partial}{\partial \mathrm{x}}\left(\mathrm{K} \frac{\partial \mathrm{T}}{\partial \mathrm{x}}\right)+\frac{\partial}{\partial \mathrm{y}}\left(\mathrm{K} \frac{\partial \mathrm{T}}{\partial \mathrm{y}}\right)+\frac{\partial}{\partial z}\left(\mathrm{~K} \frac{\partial \mathrm{T}}{\partial \mathrm{z}}\right)+\mathrm{Q}_{\mathrm{V}}
\end{aligned}
$$

where the specific heat, thermal conductivity, volumetric heat source are represented by $C_{p}, \mathrm{~K}$ and $Q_{v}$, respectively. The static temperature, $\mathrm{T}$ is calculated from the total temperature with $v$ as the magnitude of the fluid velocity vector specified below in the absence state of heat transfer, adiabatic incompressible case:

$$
\mathrm{T}=\mathrm{T}_{\mathrm{o}}-\frac{\mathrm{v}^{2}}{{ }^{2} \mathrm{Cp}}
$$

In the incompressible fluid flow state, the viscous work, pressure work, viscous dissipation and kinetic energy are neglected in the compression case which can best be referred to (ANSYS Inc., 2009).

For the calculation of the pressure, the defining expression for the relative pressure is:

$$
\mathrm{P}_{\text {abs }}=\mathrm{P}_{\text {ref }}+\mathrm{P}_{\text {rel }}-\rho_{\mathrm{o}}\{\mathrm{g}\} \cdot\{\mathrm{r}\}+\frac{1}{2} \rho_{\mathrm{o}}(\{\omega\} \times\{\omega\} \times\{\mathrm{r}\}) \cdot\{\mathrm{r}\}
$$

Combining the momentum equations into vector form, the result is changed to:

$$
\rho \frac{\mathrm{D}\{v\}}{\mathrm{Dt}}+2 \rho\{\omega\} \times\{v\}+\rho\{\omega\} \times\{\omega\} \times\{\mathrm{r}\}=\rho\{\mathrm{g}\}-\nabla \mathrm{P} \text { abs }+\mu \nabla^{2}\{v\}
$$

where $\rho_{o}, P_{r e f},\{g\}, P_{a b s}, P_{r e l},\{r\},\{w\},\{v\}, \mu$, and $\{\rho\}$ are the reference density, reference pressure, gravity vector, absolute pressure, relative pressure, position vector of fluid particle relating to rotating coordinate system, angular velocity vector, velocity vector in global coordinate system, fluid viscosity and fluid density respectively. For the case of two-way coupling in fluid flow, moving interfaces are included with the effect on the structural deformation that will deform the fluid mesh. Such phenomenon changes with time and needs to satisfy the boundary conditions at the moving interfaces. Arbitrary Lagrangian-Eulerian (ALE) formulation (Thomas, 2010; ANSYS Inc., 2009; Donea et al., 2003) has been applied in solving such a problem, this can be found in (Joris et al., 2010; Bathe et al., 2009).

\subsubsection{Arbitrary Lagrangian Eulerian, ALE Formulation}

ALE algorithms are particularly useful in flow problem solutions which involve large distortions in the case of mobile and deforming boundaries available within the interaction between a fluid and a flexible structure such as FSI (ANSYS Inc., 2009). Fluid flow problems often involve moving interfaces which include moving internal 
walls (for example, a solid moving through a fluid), external walls or free surfaces. ALE formulations will become useful to solve such a problem as shown in (Donea et al., 2003). Eulerian equations of motion need to be modified to reflect the moving frame of reference. The time derivative terms are essentially rewritten in terms of the moving frame of reference where $\phi$ and $\vec{w}$ are the degree of freedom and velocity of the moving frame of reference, respectively as shown below:

$$
\left.\frac{\partial \phi}{\partial \mathrm{t}}\right|_{\text {fixedframe }}=\left.\frac{\partial \phi}{\partial \mathrm{t}}\right|_{\text {movingframe }}-\overrightarrow{\mathrm{w}} \cdot \nabla \phi
$$

With the robust and versatile software, ANSYS, three-dimensional models of FSI can be applied and solved in some numerical examples. However, various research has been conducted in the applications of ALE which can be referred to in Bathe (2009) and Wulf \& Djordje (2008). Such algorithms are applicable in the monolithic or partitioned manner in mitigating FSI problems. The functions of FLOTRAN-CFD and Structural in ANSYS allow the analysis of fluid and structure domains in conjunction with different coupling analysis solution methods.

\subsubsection{Segregation Solution Algorithm}

In the case of coupling algorithms, the pressure and momentum equations are coupled with the SIMPLEF algorithm originally belonging to a general class referred to as the Semi-Implicit Method for Pressure Linked Equations (SIMPLE). SIMPLEF is the sole pressure-velocity coupling algorithm developed by Schnipke and Rice (1985) with the further improved SIMPLE-Consistent algorithm by Van Doormaal and Raithby (1984). An approximation of the velocity field is obtained by solving the momentum equation. The pressure gradient term is calculated by using the pressure distribution from the previous iteration or an initial guess. The pressure equation is then formulated and solved in order to obtain the new pressure distribution. Velocities are corrected and a new set of conservative fluxes is calculated. The implementation of the SIMPLEF algorithm can best be referred to in (ANSYS Inc., 2009).

\subsection{Solid Structure Governing Equations}

The solid structure equation is based on the impulse conservation that is solved by using a finite element approach as shown below where $M, C, K, \overrightarrow{\ddot{u}}, \overrightarrow{\dot{u}}$ and $\vec{u}$ are the mass, damping coefficient, stiffness, acceleration, velocity, and displacement vectors, respectively as described in (Zienkiewicz \& Taylor, 2005):

$$
\mathrm{M} \cdot \overrightarrow{\mathrm{u}}+\mathrm{C} \cdot \overrightarrow{\dot{\mathrm{u}}}+\mathrm{K} \cdot \overrightarrow{\mathrm{u}}=\overrightarrow{\mathrm{F}}
$$

The computed equivalent strain is shown as:

$$
\varepsilon_{\mathrm{e}}=\frac{1}{1+v^{\prime}}\left(\frac{1}{2}\left[\left(\varepsilon_{1}-\varepsilon_{2}\right)^{2}+\left(\varepsilon_{2}-\varepsilon_{3}\right)^{2}+\left(\varepsilon_{3}-\varepsilon_{1}\right)^{2}\right]\right)^{\frac{1}{2}}
$$

The equivalent stress (von Mises) related to the principal stress can be obtained from

$$
\sigma_{\mathrm{e}}=\left[\frac{\left(\sigma_{1}-\sigma_{2}\right)^{2}+\left(\sigma_{2}-\sigma_{3}\right)^{2}+\left(\sigma_{3}-\sigma_{1}\right)^{2}}{2}\right]^{\frac{1}{2}}
$$

where $\sigma_{e}$ is the equivalent stress of any arbitrary three-dimensional stress state to be represented as a single positive stress value. The equivalent stress is part of the maximum equivalent stress failure theory known as yield functions which can be referred to in Zienkiewicz and Taylor (2005).

The general element formulation used for SOLID185 is the fundamental equation applicable for general finite strain deformation where the updated Lagrangian method is applied to simulate geometric nonlinearities. Convention of index notation are used in the equations below and all variables such as coordinates $x_{i}$, displacements $u_{i}$, strains $\varepsilon_{\mathrm{ij}}$, stresses $\sigma_{i j}$, velocities $v_{i}$, volume $V$ and other material variables have been assumed to be solved at time $t$. The equations are derived from the element formulations which are based on the principle of virtual work as in ANSYS Inc. (2009): 


$$
\int_{\mathrm{v}} \sigma_{i j} \delta e_{i j} d V=\int_{s} f_{i}^{B} \delta u_{i} d V+\int_{s} f_{i}^{S} \delta u_{i} d s
$$

where $\sigma_{i j}, e_{i j}, u_{i}, x_{i}, \mathrm{f}_{\mathrm{i}}^{\mathrm{B}}$ and $\mathrm{f}_{\mathrm{i}}^{\mathrm{S}}$ are the Cauchy stress component, deformation tensor, displacement, current coordinates $(x, y$ and $z$ ), component of body force and component of surface traction, respectively. The volume of deformed body, $V$, and surface traction of deformed body, $S$, were represented in Equation (16) as well. The internal virtual work, $W$, can be described as:

$$
\delta \mathrm{W}=\int_{\mathrm{V}} \sigma_{\mathrm{ij}} \delta \mathrm{e}_{\mathrm{ij}} \mathrm{dV}
$$

The element formulations are obtained by differentiating the virtual work and in the derivation, only the linear differential terms are kept and all higher order terms are ignored just to obtain a linear set of equations. The Mmaterial constitutive law was used to create the relation between stress increment and strain increment which reflects the stress increment due to straining. The Jaumann rate of Cauchy stress expressed by McMeeking and Rice (1975) was applied in the constitutive law because the Cauchy stress is affected by the rigid body rotation which is not a frame invariant (ANSYS Inc., 2009).

$$
\dot{\sigma}_{i j}^{J}=\dot{\sigma}_{i j}-\sigma_{i k} \dot{\omega}_{j k}-\sigma_{j k} \dot{\omega}_{i k}
$$

where $\dot{\sigma}_{\mathrm{ij}}^{J}$ is the Jaumann rate of Cauchy stress and $\dot{\sigma}_{i j}$ is the time rate of Cauchy stress.

The spin tensor $\dot{\omega}_{\mathrm{ij}}$ can be expressed as:

$$
\dot{\omega}_{i j}=\frac{1}{2}\left(\frac{\partial v_{i}}{\partial x_{j}}-\frac{\partial v_{j}}{\partial x_{i}}\right)
$$

Thus, the Cauchy stress rate is:

$$
\dot{\sigma}_{i j}=\dot{\sigma}_{i j}^{J}+\sigma_{i k} \dot{\omega}_{j k}+\sigma_{j k} \dot{\omega}_{i k}
$$

The rate of deformation tensor $d_{i j}$ can be expressed as:

$$
d_{i j}=\frac{1}{2}\left(\frac{\partial_{v i}}{\partial x_{j}}+\frac{\partial_{v j}}{\partial x_{i}}\right)
$$

The stress change due to straining based on the constitutive law is shown as:

$$
\dot{\sigma}_{i j}^{J}=c_{i j k l} d_{k l}
$$

And the Cauchy stress rate can now be expressed as:

$$
\dot{\sigma}_{\mathrm{ij}}=\mathrm{c}_{\mathrm{ijkl} \mathrm{kl}} \mathrm{d}_{\mathrm{ik}}+\sigma_{\mathrm{jk}} \dot{\omega}_{\mathrm{jk}}+\sigma_{\mathrm{ik}}
$$

where $\mathrm{c}_{\mathrm{ijkl}}$ and $\mathrm{v}_{\mathrm{i}}$ are the material constitutive tensor and velocity, respectively.

\subsection{Coupled-Field Analysis Methods}

Multi-Field Analysis with Single-Code Coupling (MFS) (ANSYS Inc., 2009) and Load Transfer Coupled Physics Analysis (ANSYS Inc., 2009) are the two sequential or partitioned coupling solvers in the ANSYS Mechanical APDL. The MFS coupling solver is considered as a strongly coupled system as shown in Figure 4 whereas the weakly coupled system shown in Figure 3. Both methods are categorised by the load transfer coupling that involves two or more calculations where each belongs to a different field with interaction in between. This will allow load transfer from one result of an analysis to another. 


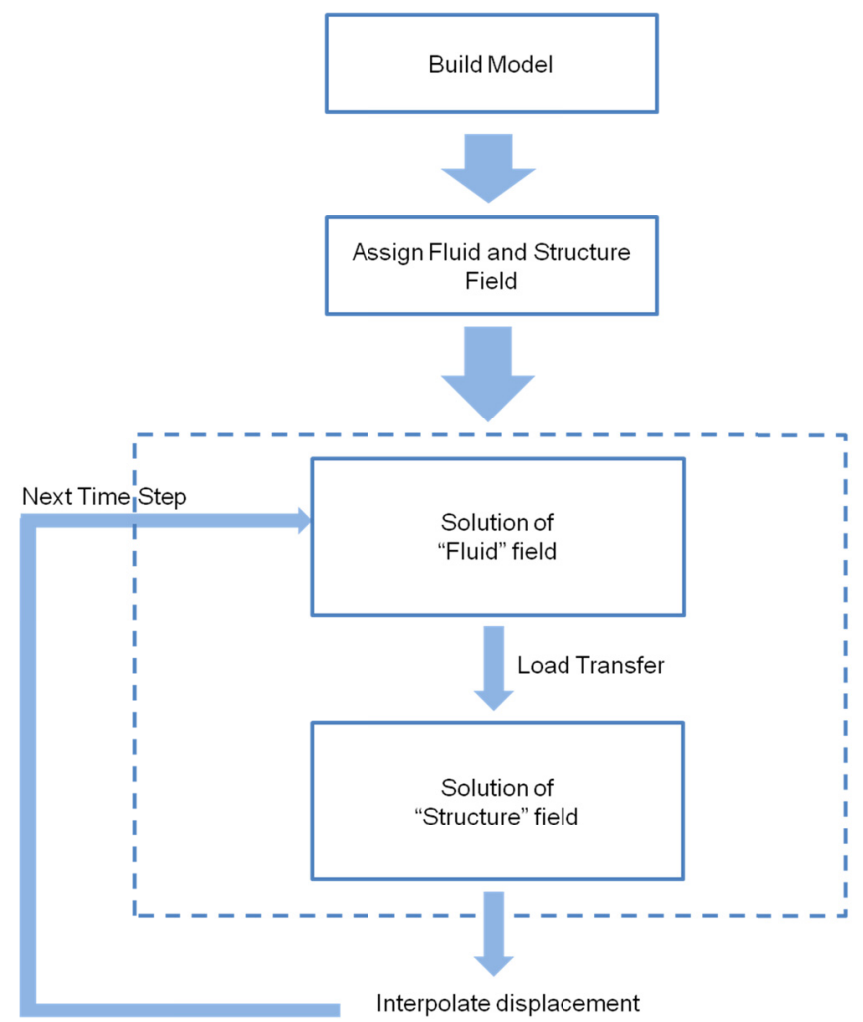

Figure 3. Weak two-way coupling system (load transfer physics environment)

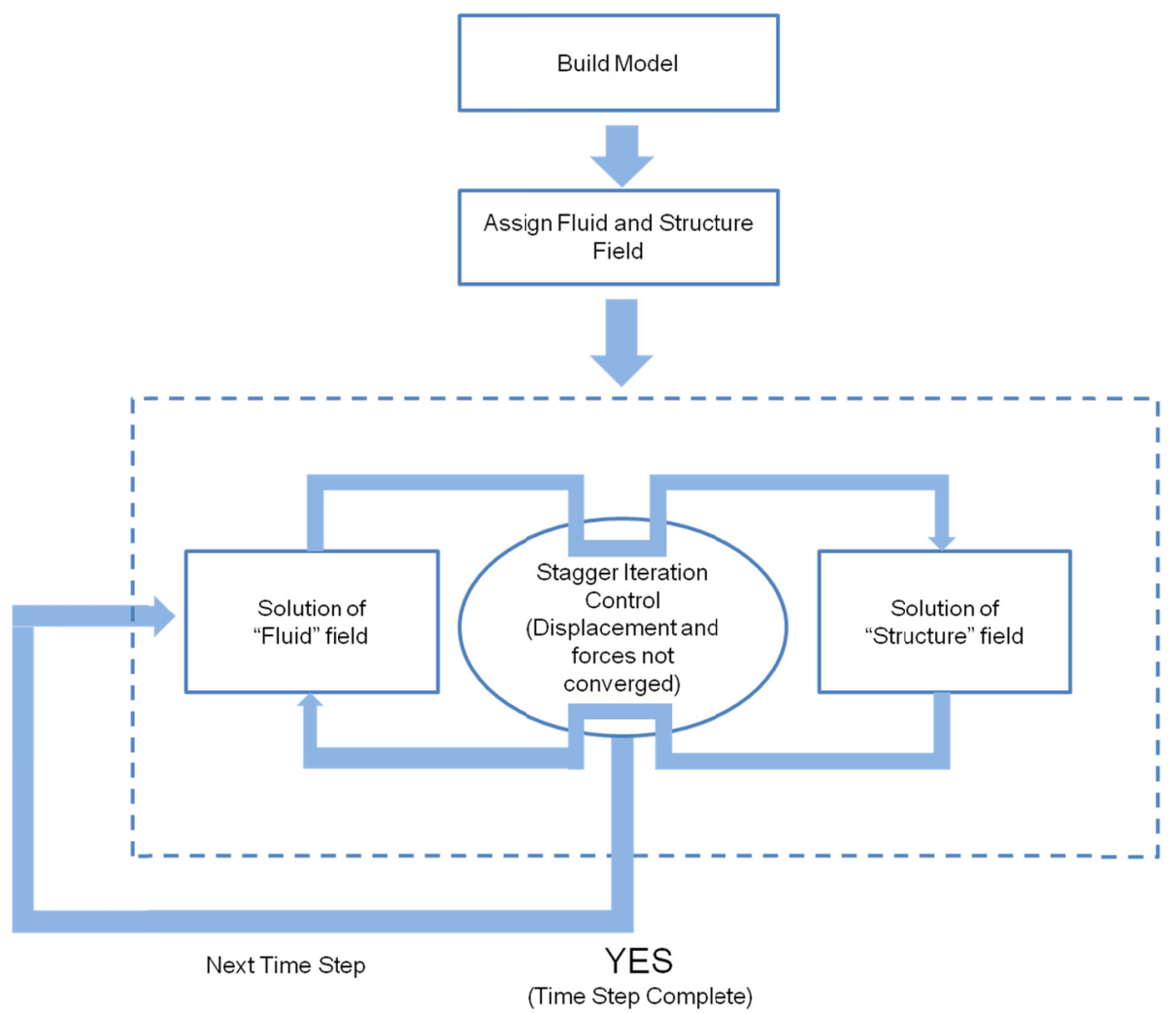

Figure 4. Strong two-way coupling system (Multi-Field Solver, MFS) 


\section{Concrete Gravity-Dams Reservoir Analysis}

A hypothetical concrete gravity-dam water reservoir in Oued-Fodda, Algeria (Tiliouine \& Seghir, 1998) has been used as shown in Figure 5 for FSI analysis. It was truncated to $300.0 \mathrm{~m}$ in length with the assumed depth of $300.0 \mathrm{~m}$ in the consideration of a close and open spillways concrete gravity-dam case scenario. A turbulence current inflow from the dynamic effects of the recent Tohoku earthquake in Japan, 2011 was applied which induced a high velocity inflow of $29.63 \mathrm{~ms}^{-1}$. The actual recorded acceleration of $26.49 \mathrm{~ms}^{-2}$ at $\mathrm{t}=1.10$ second (Erol \& Volkan, 2011) was taken to be the peak horizontal inflow acceleration under that dynamic condition (Lim, 2012). All the materials' properties taken with assumption are shown in Table 1.

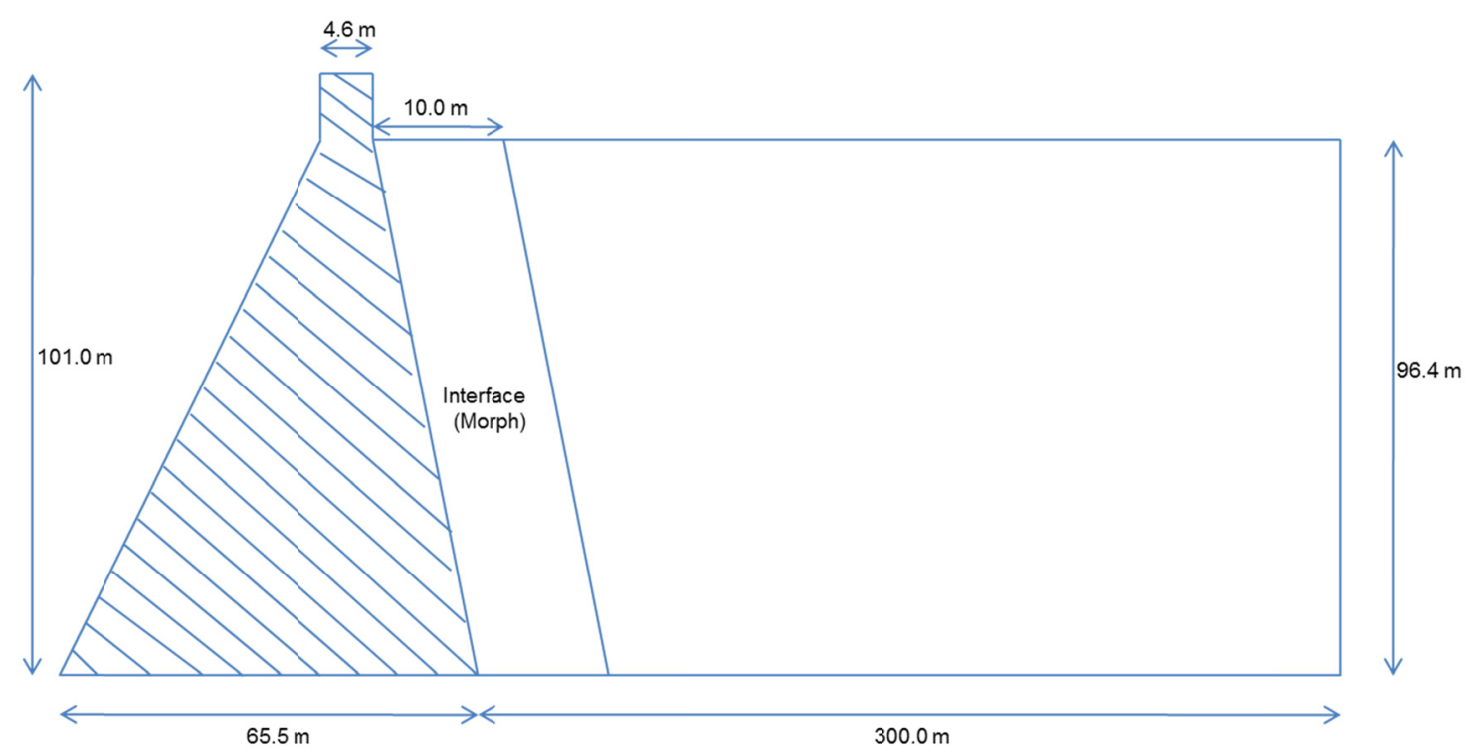

- Concrete Dam Structure (Not To Scale)

$\square$ - Reservoir (water) (Not To Scale)

Figure 5. Hypothetical model of the concrete gravity-dam structure in Oued-Fodda, Algeria

Table 1. Material properties for the concrete gravity-dams and water-reservoirs

\begin{tabular}{ccccc}
\hline Materials & $\begin{array}{c}\text { Elastic Modulus } \\
(\mathrm{GPa})\end{array}$ & Poisson Ratio's & $\begin{array}{c}\text { Density } \\
\left(\mathrm{kg} / \mathrm{m}^{3}\right)\end{array}$ & $\begin{array}{c}\text { Viscosity } \\
\left(\mathrm{x} \mathrm{10} 0^{-4} \text { Pa.s }\right)\end{array}$ \\
\hline $\begin{array}{c}\text { Concrete } \\
\text { (High-Strength) }\end{array}$ & 30 & 0.2 & 2400 & - \\
Water & - & - & 1000 & 8.9 \\
\hline
\end{tabular}

\subsection{Results and Discussion}

\subsubsection{Close-Spillway Concrete Dam Structure}

In the comparison of the MFS method and the physics environment method, the results obtained for the close-spillway dam structure of the hydrodynamics pressure and von Mises stress are fairly reasonable and agreeable in terms of their distribution patterns. Five different node locations were selected in the close-spillway dam structure and water-reservoir respectively as depicted in Figure 6 and Figure 7 to obtain hydrodynamics pressure and von Mises results, to validate and compare both methods. Comparison of the average hydrodynamics pressure and von Mises stresses for the different node locations are demonstrated in Figure 8 and Figure 9 respectively. The distribution patterns for the pressures and stresses of both methods in comparison are quite similar for all the locations. The recorded maximum average ratio values between them are 1.147 (node location 5) for pressure and 2.600 (node location 5) for stress. It has an overall average ratio of 1.031 for the 
pressure and 2.321 for the stress, respectively. The difference in the stress may be caused by strong two-way MFS analysis solution that requires longer staggering iterations in achieving a full convergence at the strong coupling of interface(s). This is in comparison with the load transfer physics environment method of weak two-way coupling which could converge easily in a weak coupling system. The trends of both graphs oscillate with almost similar patterns and distributions. The overall average ratios for comparison can best refer to Table 2.

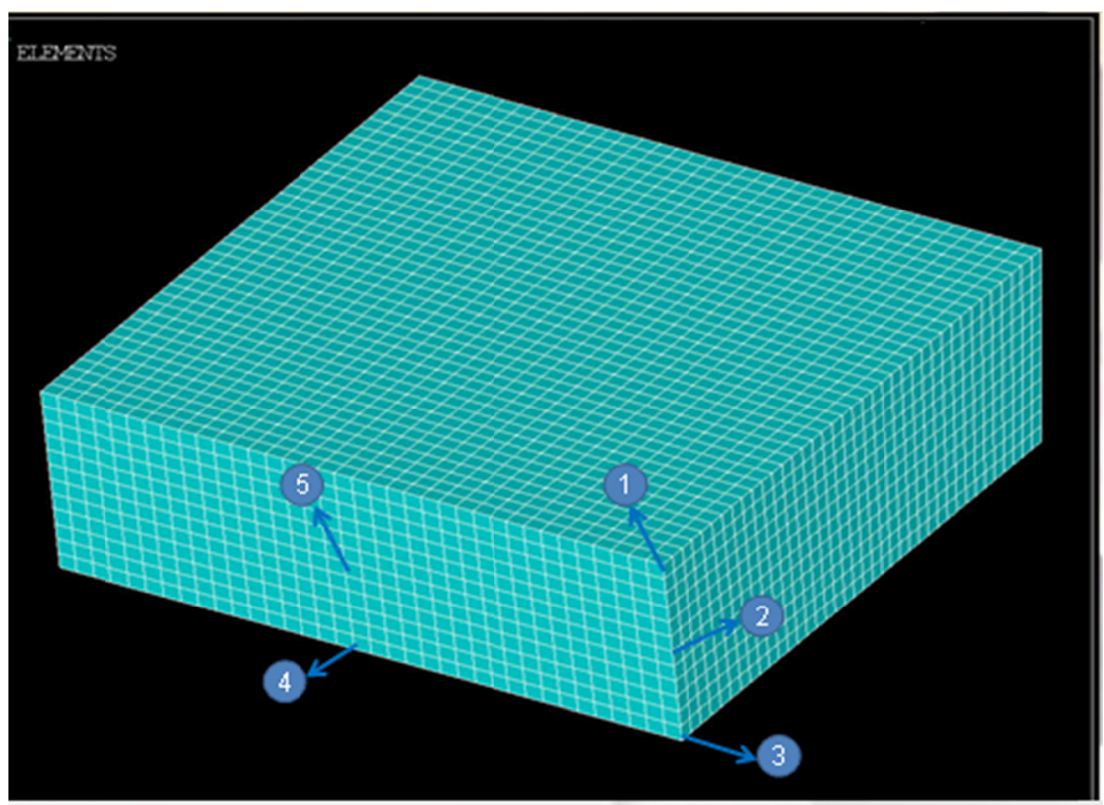

Figure 6. Nodes location of the water-reservoir domain for the comparison of hydrodynamics pressure results (close-spillway)

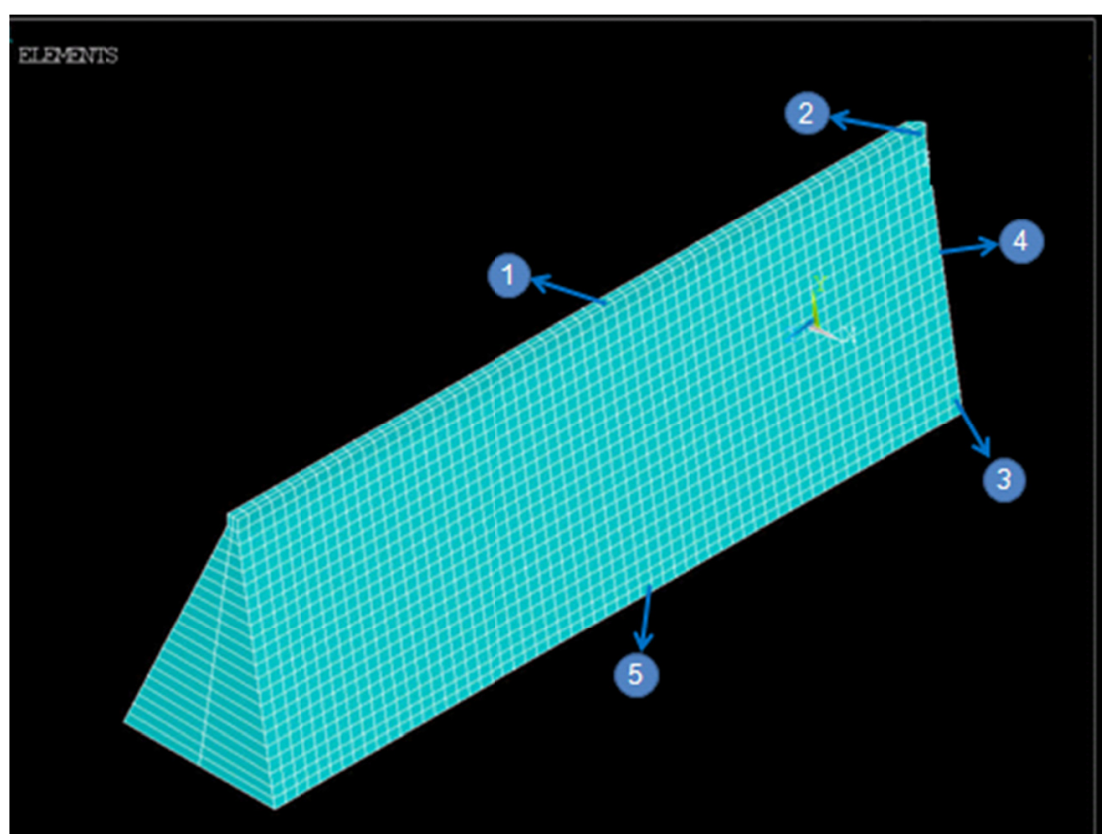

Figure 7. Nodes location of the concrete-dam domain for the comparison of von Mises stress results (close-spillway) 


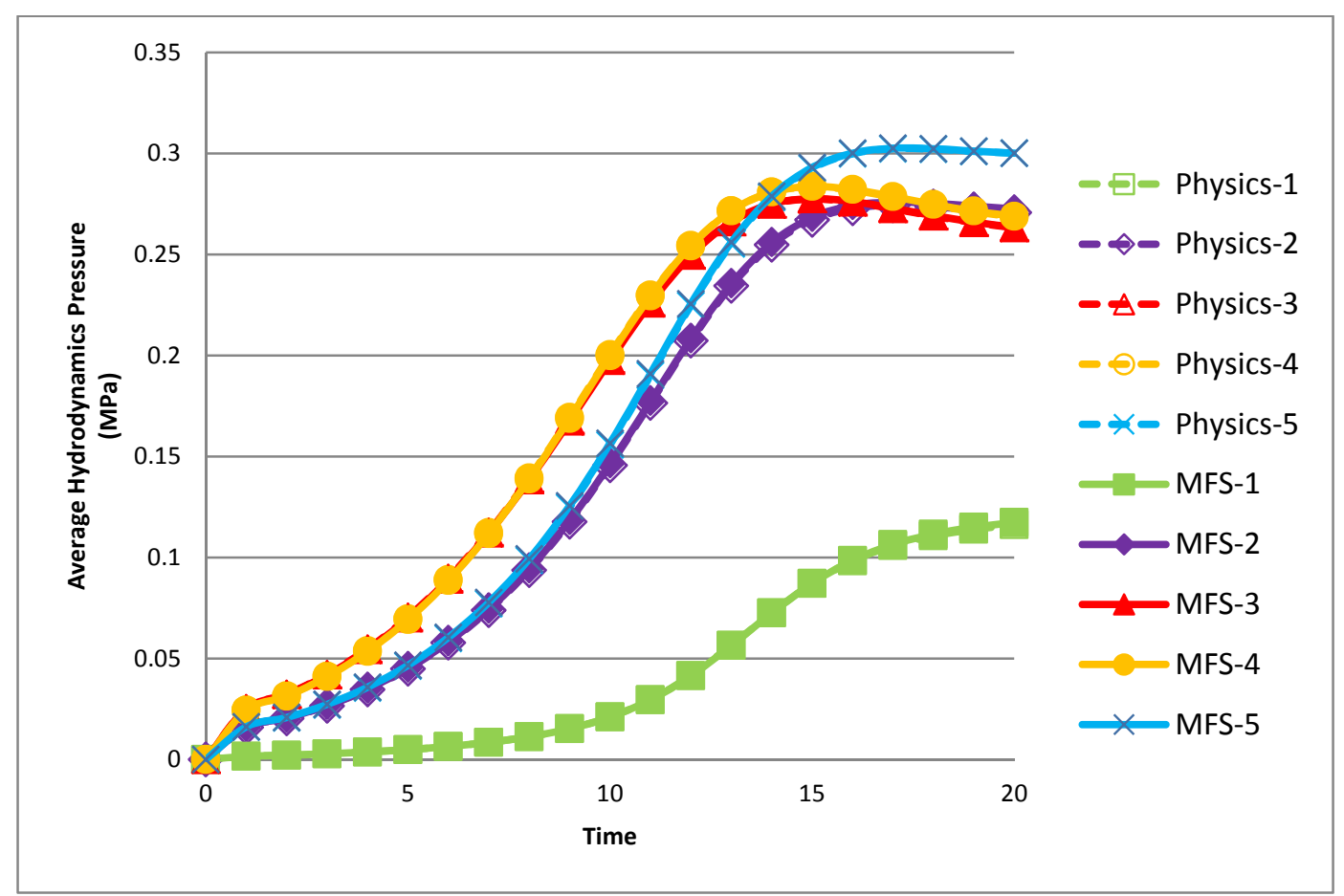

Figure 8. Comparison of the average hydrodynamics pressure of the close-spillway concrete gravity-dam reservoir for the multi-field solver between MFS (strong-coupling) with load transfer physics environment (weak-coupling)

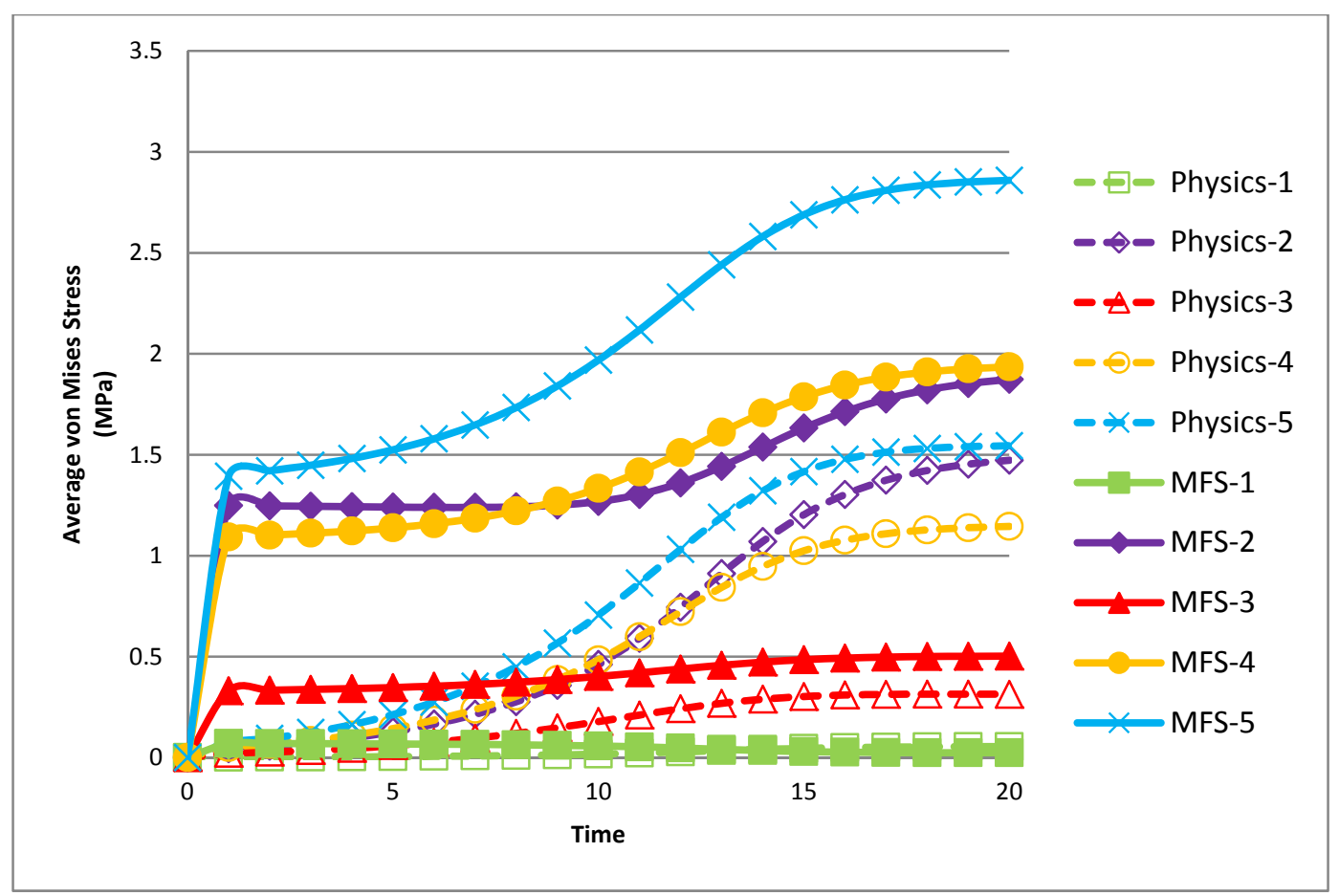

Figure 9. Comparison of the average von Mises stress of the close-spillway concrete gravity-dam reservoir for the multi-field solver between MFS (strong-coupling) with load transfer physics environment (weak-coupling) 
Table 2. Average ratio of hydrodynamic pressure and von Mises stress of both MFS and load transfer physics environment methods for the close-spillway concrete gravity-dam reservoir

\begin{tabular}{ccc}
\hline Node Location Case & $\begin{array}{c}\text { Hydrodynamics Pressure } \\
\text { (Average Ratio) }\end{array}$ & $\begin{array}{c}\text { von Mises Stress } \\
\text { (Average Ratio) }\end{array}$ \\
\hline 1 & 1.004 & 1.960 \\
2 & 1.005 & 2.256 \\
3 & 0.9988 & 2.264 \\
4 & 0.9992 & 2.523 \\
5 & 1.147 & 2.600 \\
Overall average ratio & $\mathbf{1 . 0 3 1}$ & $\mathbf{2 . 3 2 1}$ \\
\hline
\end{tabular}

\subsubsection{Open-Spillway Concrete Dam Structure}

In a further example of applications in both couple-field methods, results have been compared for the open-spillway concrete gravity-dam reservoir analysis. Five different node locations are selected for every case of the water-reservoir and concrete dam structure as shown in Figure 10 and Figure 11 to illustrate the comparison of hydrodynamics pressure and von Mises stress. The distribution patterns of the hydrodynamics pressures and von Mises stresses are agreeable to the selected five crucial node locations as shown in Figure 12 and Figure 13 with the recorded maximum average ratio value of 1.412 for pressure (node location 2) and 1.816 for stress (node location 5). For the computed results of the open-spillway concrete gravity-dam structure, it has been shown that the overall average ratio for both pressure and stress are 1.260 and 1.474, respectively. This is closely similar to the previous case and the overall average ratios for this case can be seen in Table 3 . The difference in results could be contributed by the reason of the strong coupling system between the interactions in MFS method and its staggering iterations between fields analysis. This has also caused the computational time duration to be longer than that of the load transfer physics environment method. Hence, in these computing applications, the results obtained have justified the applications of both methods in solving the FSI problems although the strong coupling algorithm maybe more difficult and stringent in convergence compared to the weak coupling algorithm in terms of large surface area of interaction within the complex numerical model.

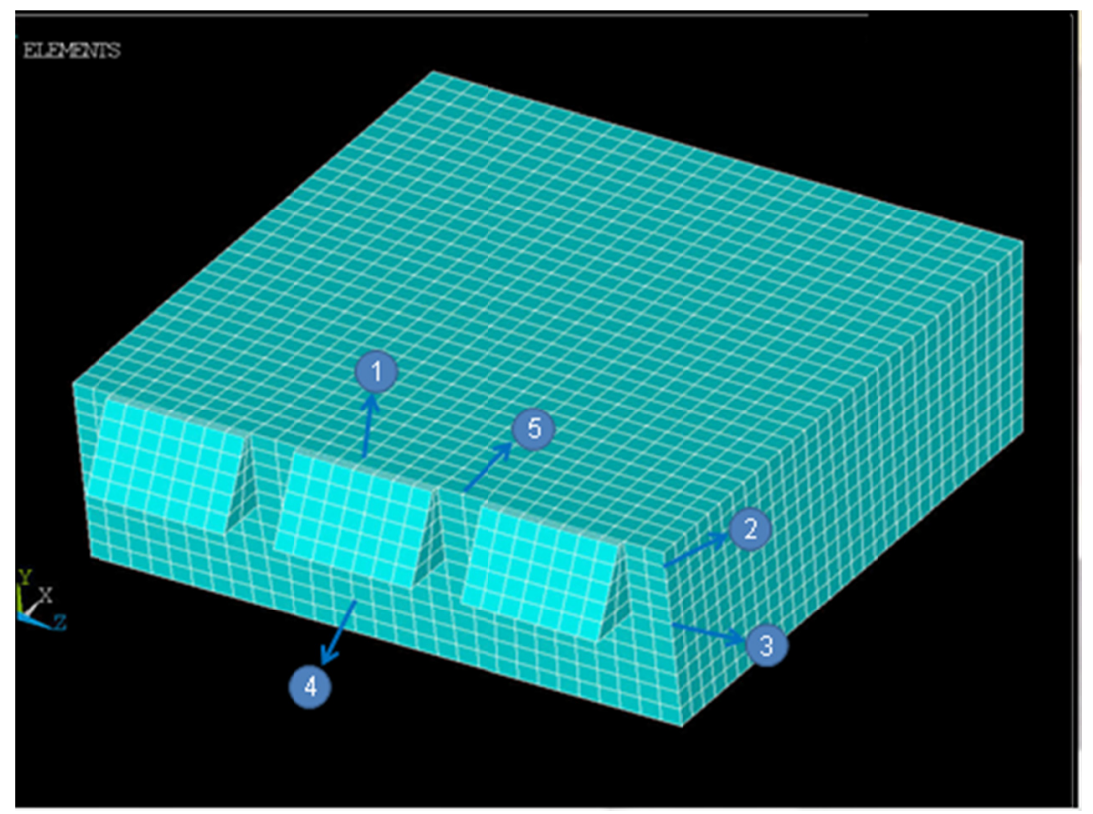

Figure 10. Nodes locations in the water-reservoir domain for the comparison of hydrodynamics pressure results (open-spillway) 


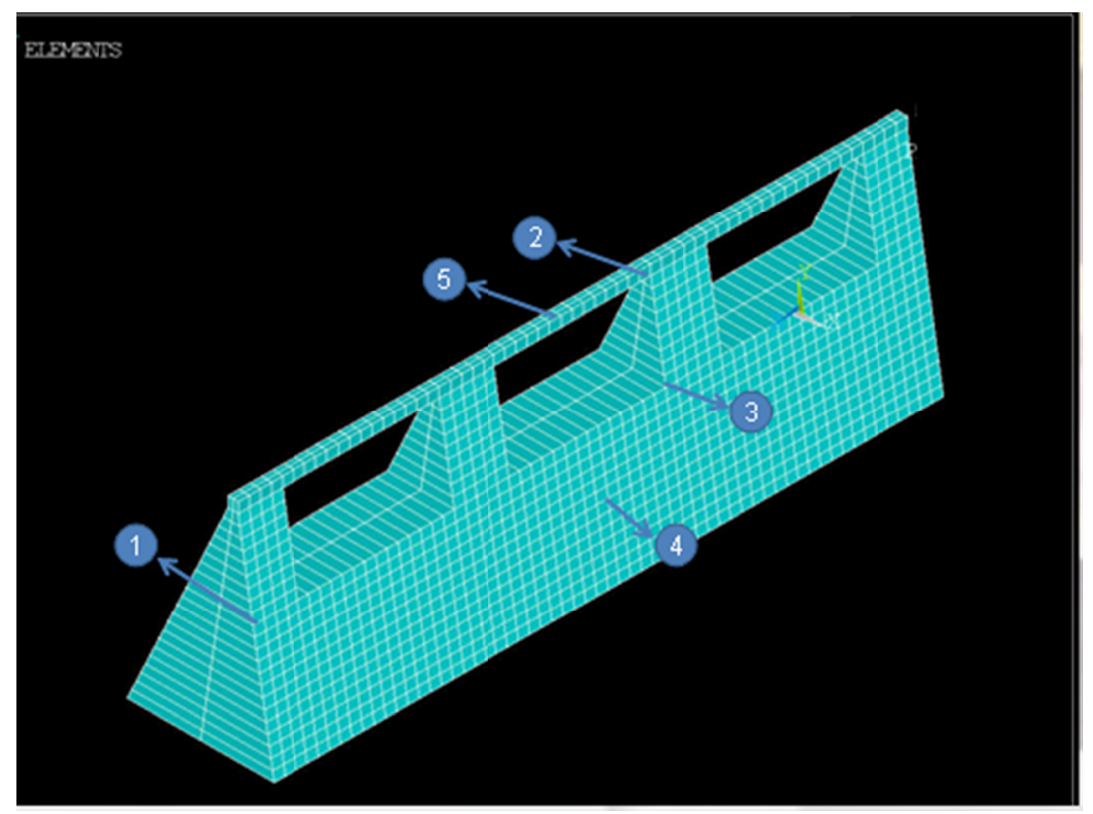

Figure 11. Nodes location of the concrete dam structure domain for the comparison of von Mises stress results (open-spillway)

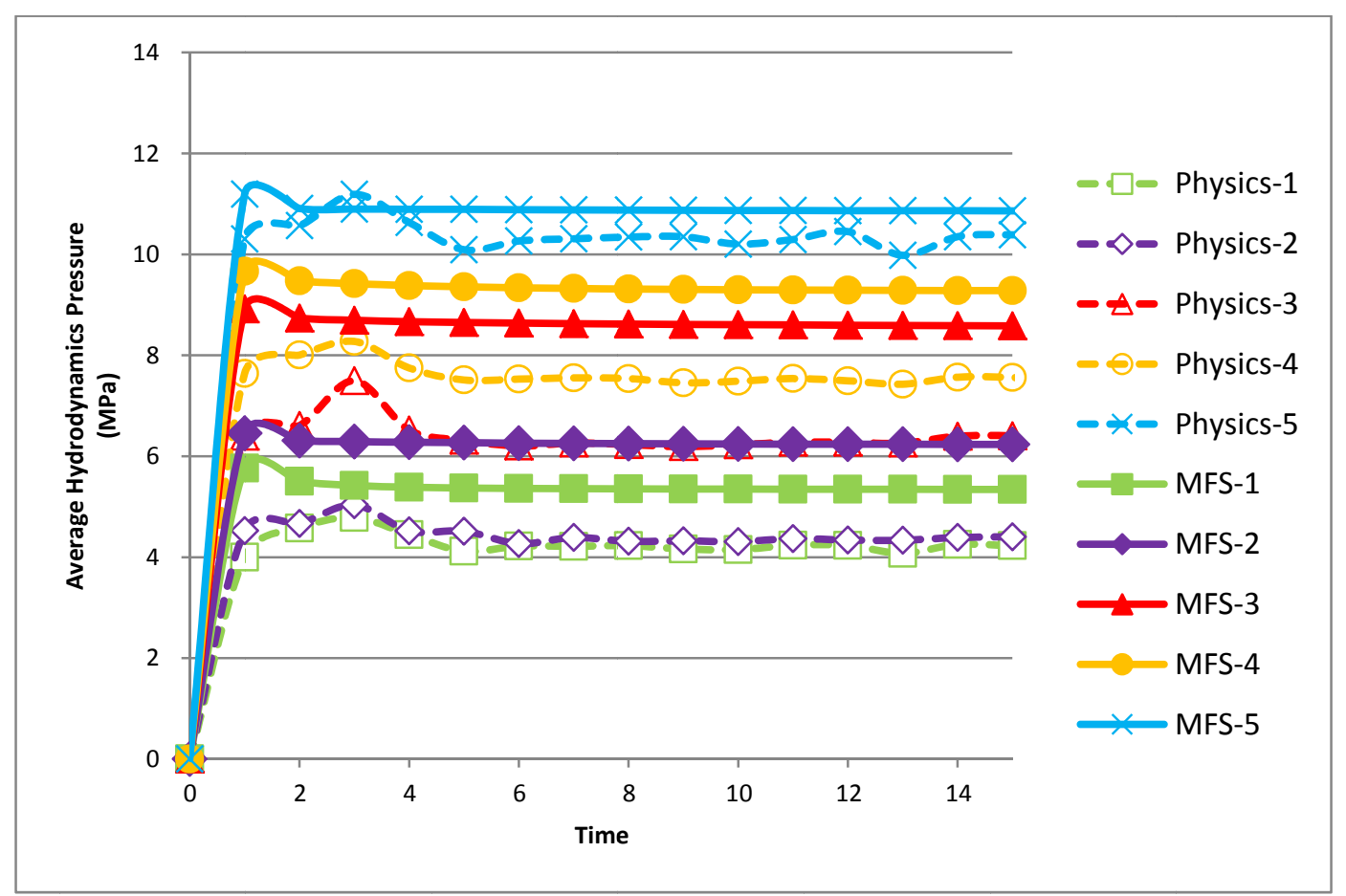

Figure 12. Comparison of the average hydrodynamics pressure of the open-spillway concrete gravity-dam reservoir for the multi-field solver between MFS (strong-coupling) with load transfer physics environment (weak-coupling) 


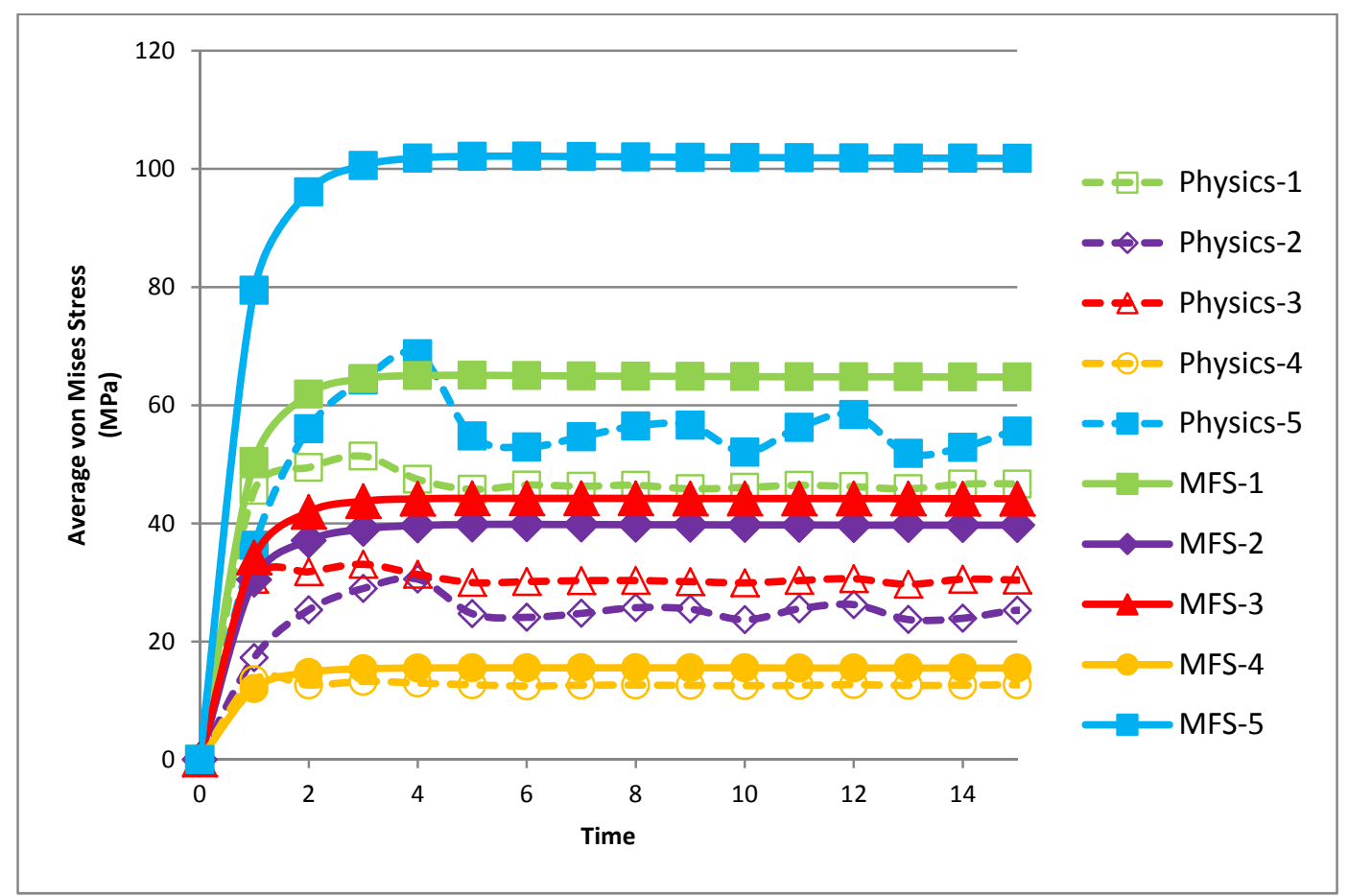

Figure 13. Comparison of the average von Mises stress of the open-spillway concrete gravity-dam reservoir for the multi-field solver between MFS (strong-coupling) with load transfer physics environment (weak-coupling)

Table 3. Average ratio of hydrodynamic pressure and von Mises stress of both MFS and load transfer physics environment methods for the open-spillway concrete gravity-dam reservoir

\begin{tabular}{ccc}
\hline Node Location Case & $\begin{array}{c}\text { Hydrodynamics Pressure } \\
\text { (Average Ratio) }\end{array}$ & $\begin{array}{c}\text { von Mises Stress } \\
\text { (Average Ratio) }\end{array}$ \\
\hline 1 & 1.260 & 1.369 \\
2 & 1.412 & 1.560 \\
3 & 1.350 & 1.425 \\
4 & 1.228 & 1.200 \\
5 & 1.049 & 1.816 \\
Overall average ratio & $\mathbf{1 . 2 6 0}$ & $\mathbf{1 . 4 7 4}$ \\
\hline
\end{tabular}

\section{Conclusions}

Numerical examples have been used in this paper to illustrate the differences between the coupling algorithms for both strongly and weakly coupled partitioned methods with techniques adopted such as the Lagrangian and ALE with FEM techniques. The feasibility and capability of both methods have been tested and compared on a large scale three dimensional concrete gravity reservoir dam. From the numerical results obtained, it has been proved that both weak and strong coupled field methods are oscillating with the same pressure and stress distributions which both justify their capabilities of transferring load between the surfaces of interaction. In both examples, the dam structures have responded to the pressure impact through the interaction surface or region with the distribution patterns being similar. However, the differences of average ratio in the stress value could be caused by the stringent convergence in the strong coupling algorithm due to the large surface interactions of the numerical model whereas the weak coupling algorithm has loose convergence within the surface of interaction. Therefore, the strong coupling algorithm could be justified to obtain more realistic results, however its strict convergence requirement for the large interaction surface may need longer computational time and initiate instability for computing. Hence, the weak two-way coupling algorithm could be an ideal method in solving both small and large scale numerical models without any convergence problems within the interaction surfaces. 


\section{Acknowledgement}

The authors are grateful for a PhD scholarship provided by the Faculty of Engineering, Built Environment and Science of London South Bank University to Mr W. Z. Lim to allow this research to be conducted.

\section{References}

Akkose, M., Adanur, S., Bayraktar, A., \& Dumanoglu, A. A. (2008). Elasto-plastic earthquake response of arch dams including fluid-structure interaction by the Lagrangian approach. Applied Mathematical Modelling, 32, 2396-2412. http://dx.doi.org/10.1016/j.apm.2007.09.014

ANSYS Inc. (2009). Documentation, Release 12.0. USA, April 2009 (pp. 1325-1340).

Bathe, K. J., \& Zhang, H. (2009). A mesh adaptivity procedure for CFD and fluid-structure interactions. Computers and Structures, 87, 604-617. http://dx.doi.org/10.1016/j.compstruc.2009.01.017

Benra, F. K., Dohmen, H. J., Pei, J., Schuster, S., \& Wan, B. (2011). A Comparison of One-Way and Two-Way Coupling Methods for Numerical Analysis of Fluid-Structure Interactions. Journal of Applied Mathematics, 2011.

Broderick, L. L., \& Leonard, J. W. (1989). Selective review of boundary element modelling for the interaction of deformable structures with water waves. Oregon State Unversity, Corvalli (September 1989).

Donea, J., \& Huerta, A. (2003). Introduction and Preliminaries. In: John Wiley \& Sons Ltd, Finite Element Method for Flow Problems, England (pp. 1-32).

Erol, K., \& Volkan, S. (2011). M9.0 Tohoku, Japan Earthquake: Preliminary results. United States Geological Survey, 17th March 2011.

Jo, J. C. (n.d.). Fluid-structure interactions. Korea Institute of Nuclear Safety, Republic of Korea.

Joris, D., Robby, H., Sebastiaan, A., Peter, B., \& Jan, V. (2010). Performance of partitioned procedures in fluid-structure interaction. Computers and Structures, $446-457$. http://dx.doi.org/10.1016/j.compstruc.2009.12.006

Lim, W. Z., Xiao, R. Y., \& Chin, C. S. (2012). A Comparison of Fluid-Structure Interaction Methods for a Simple Numerical Analysis of Concrete Gravity-Dam. Proceedings of the $20^{\text {th }}$ UK Conference of the Association for Computational Mechanics in Engineering, 27-28th March 2012, University of Manchester, Manchester.

McMeeking, R. M., \& Rice, J. R. (1975). Finite element formulations for problems of large elastic-plastic deformation. International Journal Solids $\quad$ Structures, $\quad 11, \quad 601-616$. http://dx.doi.org/10.1016/0020-7683(75)90033-5

Michler, C., Hulshoff, S. J., van Brummelen, E. H., \& de Borst, R. (2003). A monolithic approach to fluid-structure interaction. Faculty of Aerospace Engineering, Delft University of Technology, The Netherland, (25 ${ }^{\text {th }}$ March 2003).

Mitra, S., \& Sinhamahapatra, K. P. (2008). 2D simulation of fluid structure interaction using finite element method. Finite Elements in Analysis and Design, 45, 52-59. http://dx.doi.org/10.1016/j.finel.2008.07.006

Onate, E., Idelsohn, S. R., Celigueta, M. A., \& Rossi, R. (2007). Advances in the particle finite element method for the analysis of fluid-multibody interaction and bed erosion in free surface flows. International Center for Numerical Methods in Engineering (CIMNE), Technical University of Catalonia, Barcelona, Spain (4th June 2007).

Sandboge, R. (2010). Fluid-structure interaction with OpenFSI and MD Nastran structural solver. MS Software Corporation, USA (5th March 2010).

Schnipke, R. J., \& Rice, J. G. (1985). Application of a new finite element method to convection heat transfer. In Fourth International Conference on Numerical Methods in Thermal Problems, July 1985, Swansea, UK.

Thomas Richter. (23th July, 2010). Numerical methods for fluid-structure interaction problems. Heidelberg.

Tiliouine, B., \& Seghir, A. (1998). Fluid-structure models for dynamic studies of dam-water systems. Eleventh European Conference on Earthquake Engineering (pp. 6-11), September Paris, France.

Van Doormaal, J. P., \& Raithby, G. D. (1984). Enhancements of the SIMPLE method for predicting incompressible fluid flows. Numerical Heat Transfer, 7, 147-163. http://dx.doi.org/10.1080/01495728408961817 
Walhorn, E., Kolke, A., Hubner, B., \& Dinkler, D. (2005). Fluid-structure coupling within a monolithic model involving free surface flows. Institut für Statik, Technische Universita"t Braunschweig, Beethovenstr. 51, 38106 Braunschweig, Germany (2nd March 2005).

Wulf, G. D., \& Djordje, P. (2008). On the coupling between fluid flow and mesh motion in the modelling of fluid-structure interaction. Comput Mech, 43, 81-90. http://dx.doi.org/10.1007/s00466-008-0254-6

Zienkiewicz, O. C., \& Taylor, R. L. (2005). Inelastic and Non-Linear Materials. In Butterworth-Heinemann, Elsevier Ltd, The Finite Element Method for Solid and Structural Mechanics (6th ed., pp. 61-120).

\section{Copyrights}

Copyright for this article is retained by the author(s), with first publication rights granted to the journal.

This is an open-access article distributed under the terms and conditions of the Creative Commons Attribution license (http://creativecommons.org/licenses/by/3.0/). 